\title{
INDIGENOUS MOLECULAR SCISSORS FROM LABORATORY MICROBES - ISOLATION AND EVALUATION OF RESTRICTION DIGESTION EFFICACIES
}

\author{
Jayaprada Rao Chunduri \\ Department of Biotechnology \\ Mithibai College of Arts, Chauhan Institute of \\ Science andnAmrutben Jivanlal College of \\ Commerce and Economics, \\ Vile Parle (West), Mumbai - 400056.
}

\author{
Nidhi Mayur Loday \\ Clinical study Associate, \\ Tata Consultancy Services, \\ MUMBAI.
}

\begin{abstract}
Enzymes are important for the metabolic activities, self-protection and survival of the bacteria as well as are sources for the toxin production. Most of the bacterial enzymes are used in textile, food, pharmaceutical and in various different industries. Bacterial enzymes also play an important role in molecular biology techniques. Molecular scissors are available commercially, characterized with known activity. An attempt has been made to isolate, identify the bacteria and assess the potential of bacteria as an indigenous source of restriction enzymes. Bacterial enzymes from known laboratory microorganisms, capable of working as molecular scissors have been identified during the current study which can be compared to commercial kits. The indigenous procedure found to be easy, possible at laboratory levels with low production cost and efficient performance levels to obtain restriction enzymes.
\end{abstract}

Keywords: molecular scissors, microbes, enzymes, low production cost

\section{INTRODUCTION}

All living organisms irrespective of their unicellular or multicellular origin comprise a set of instructions stored in their DNA- deoxyribonucleic acid. Instructions for each metabolic activity are stored in each cell as blue prints in the genome in the form of codes (AGCT) otherwise known as bases. Nucleotides code the information into sets of nucleotide sequences called genes. Each gene represents a set of coding instructions to make a specific protein with a specific function. Each protein has been assigned a certain function. As per the requirement of the cell, and its functions, many genes will be turned on or off. The functioning of the gene enables the cell, organ, organism to function in a desired manner.

A faulty gene can cause problems for the functional expression in an organisms' phenotypic expressions. Isolation of such a gene is necessary for further studies by scientists. Restriction digestion studies play a prominent role in which the gene will be cut and cloned or simply transfected into a replicable bacterial/ artificial plasmid. The digestion of gene can be carried out by a protein which behaves like a molecular scissors as it is capable of recognizing the sequence of DNA where to cut. The molecular scissors or restriction enzymes have prominent role in the discovery and manufacturing of artificial genes which play a significant role in pharmaceuticals industry. Similarly, sequencing of DNA also requires to cut it into smaller fragments. Enzymes of the pancreatic fluids comprise such DNA digesting enzymes. But most of these enzymes are of no use for sequence work as they cut each molecule randomly and produce a heterogeneous collection of fragments of varying sizes. The molecular scissors are used as tools in such instances, as they cleave the DNA molecule at a few precisely-located sites resulting in the formation of a small set of homogeneous fragments. The rarer the site it recognizes, the smaller the number of pieces produced by a given enzyme. Number of pieces produced by an enzyme depends on the rare site it recognizes.

Molecular scissors can be synthesized naturally or artificially. Naturally, all bacterial/viral cells have a unique mechanism to protect themselves from attack from viruses, fungi, and bacteria. Inside 


\section{International Journal of Engineering Applied Sciences and Technology, 2019 \\ Vol. 4, Issue 6, ISSN No. 2455-2143, Pages 92-98 \\ Published Online October 2019 in IJEAST (http://www.ijeast.com)}

each cell lies a group of special proteins called molecular scissors. These enzymes are just like scissors. They cut the DNA of a foreign organism into pieces before it has a chance to damage the cell. These enzymes don't just randomly attack foreign DNA. Instead, their attack is more targeted. However, they can be synthesized artificially as well by industrial processes.

Restriction enzymes cleave DNA at or near specific recognition sequences known as restriction sites by making an incision on each strand. This technique has a variety of uses in biotechnological applications i.e everyday medicine, including producing insulin, antibiotics, biofuel, transgenics, modern foods, synthesis of artificial and may help us make giant leaps in medicine and green fuel production in future. The production process has been commercialized. The kits are available widely which are expensive. The quantity produced by the established protocols is less, more production time, less longevity and require appropriate facilities for their storage. There is a need to find out an alternative costeffective way to synthesize the restriction enzymes and develop a kit and to increase their longevity. Bacterial cells such as $E$. coli show a capability to protect themselves against foreign DNA or inhibit the activity of lambda phage through an enzymatically catalyzed genetic defense mechanism (Arber and Linn,1969; Seed,2015). Many restriction enzymes such as EcoB, EcoK and HindIII and KpnI were identified and isolated respectively from E-coli, Haemophilus influenza and Klebsiella pneumonia as well as the recognition sites (Kelly and Smith, 1970). The symmetry of this recognition sequence was found to be in the form of a palindrome, a nucleotide sequence in which the 5' to 3' sequence of one strand of a segment of DNA is the same as that of its complementary strand which was a basic feature of the action of the enzyme. Bacteria can be used as a natural source of restriction enzymes, as they produce these enzymes as a part of their regular metabolism.

Every restriction endonuclease named in such a way that represents both the genus and the species of the bacterium from which it was isolated, the strain number, and the order in series in which the enzyme was found. For example, EcoRI: Eco refers to the genus and species (1st letter of the genus; 1st two letters of species); $\mathrm{R}$ is the strain of E. coli; I (Roman numeral) indicates it was the first enzyme of that type isolated from E. coli RY13. Each enzyme has blade i.e. 4-6 teeth. It "scans" a DNA molecule for a particular sequence of four to six nucleotides and cuts the strands. This is known as enzyme digestion. On doublestranded DNA the recognition sequence is on both strands but runs in opposite directions. The section of DNA that the scissors cut is called a 'recognition sequence' and is usually between 4-6 base pairs long. Host DNA (DNA from the animal or plant that is being attacked) can also contain these recognition sequences. Restriction enzymes catalyze the hydrolysis of the bond between the 3'-oxygen atom and the phosphorus atom in the phosphodiester backbone of DNA. The enzymes require $\mathrm{Mg}^{2+}$ or other divalent ions for their activity. Restriction enzymes typically recognize a symmetrical sequence of DNA - palindromic sequences

Recombinant DNA technology and certain of molecular biology techniques require restriction enzyme digestion to separate DNA fragments followed by electrophoresis. The use of restriction enzymes as a tool for recombining, or joining, different DNA fragments was first illustrated by Stanford University researchers (Mertz and Davis,1972). Simple and CostEffective Restriction Endonuclease Analysis methods will be great use in typing and characterizing Human Adenoviruses (Arun Kumaret.al.,2014) where the need for active quick work restriction enzymes are needed.

Similarly, the bacteria and some yeast comprise an extra chromosomal DNA of circular shape and, varying size and numbers called plasmids which can be modified and used as vectors (carrier) in rDNA technology. Genetic information contained in the plasmid of bacteria gives some advantage over other bacteria. Yeasts are small, lemon-shaped fungal cells with plasmids most widely used eukaryotic model organisms for genetic studies, cancer research, etc.

In the current study, an attempt has been made to identify the molecular scissors and assess their restriction digestion against plasmids that are also extracted and isolated from the laboratory bacterial species. This indigenous method key target is to help most of the educational institutions to set up and incorporate their own experiments at low costs. It enables short budget, more hands-on experience for the student and with reduced waiting time in the procurement.

\section{MATERIALS AND METHODS}

For the current study, the laboratory cultures were considered for the extraction of enzymes and plasmids. The bacterial and fungal cultures considered for the current study were laboratory bacterial strains of Escherichia coli, Klebsiella pneumoniae and Staphylococcus aureus and eukaryotic fungal sps. Saccharomyces cerevisiae. Bacterial strains were cultured in sterile Nutrient Broth at $37^{\circ} \mathrm{C}$ for 24 hours. 


\section{International Journal of Engineering Applied Sciences and Technology, 2019 \\ Vol. 4, Issue 6, ISSN No. 2455-2143, Pages 92-98 \\ Published Online October 2019 in IJEAST (http://www.ijeast.com)}

Yeast was cultured in sterile Sabouraud's broth at room temperature for 24 hours. All the chemicals used were analytical grade.

\section{A. Isolation and extraction of Plasmid DNA:}

Plasmid isolation methods are of various types based on the extraction and rapidity that one can apply (Kado and Liu,1981). In the current study, the bacterial plasmid was isolated by a modified Alkaline Lysis Method (Bimboim and Doly.1979). Broth containing culture was transferred to centrifuge tubes and centrifuged at $12000 \mathrm{rpm}$ for 2 minutes. Supernatant was discarded and pellet was re-suspended in Solution I (1ml), solution II (1ml) and incubated for 10 minutes on ice followed by addition of chilled solution III $(1 \mathrm{ml})$. The mix was centrifuged at 12000 rpm for 10 minutes. Pellet was discarded and to the supernatant, twice the volume of chilled ethanol was added, mixed and kept on ice for 15 minutes. After centrifuging at $12000 \mathrm{rpm}$ for 10 minutes, the supernatant was discarded. The pellet was resuspended in $100 \mu \mathrm{l}$ Tris-EDTA buffer and stored at $4^{\circ} \mathrm{C}$.

Yeast plasmid was isolated by Phenol Chloroform Method (Sobanski and Dickinson ,1995). The culture broth was transferred in centrifuge tubes which were centrifuged at $10000 \mathrm{rpm}$ for 10 minutes. The pellet was suspended in $1 \mathrm{ml}$ Solution I. Acid washed glass beads were added until just below the level of liquid \& vortexed at maximum speed for 2 minutes. $1 \mathrm{ml}$ ice cold Solution II was added. To this, $1 \mathrm{ml}$ ice cold Solution III was added, mixed and incubated on ice for 5 minutes. The sample was treated with glass beads with an equal volume of phenolchloroform - Iso-amyl alcohol (25:24:1), vortexed and centrifuged for 2 minutes. The upper aqueous phase was transferred to a second tube and the phenolchloroform extraction repeated. The aqueous upper layer was transferred to another tube and plasmid DNA was precipitated with 2 volumes of chilled ethanol ($20^{\circ} \mathrm{C}$ ) plus 0.1 volume of Sodium acetate, $\mathrm{pH}$ 6.0. After incubation for 30 minutes on ice, plasmid DNA was pelleted by centrifugation at room temperature for 10 minutes. Pellet was washed with $1 \mathrm{ml} 70 \%$ ethanol and air dried. Plasmid DNA was suspended in Tris - EDTA buffer, $\mathrm{pH} 8.0$ and stored at $4^{\circ} \mathrm{C}$. The TAE based AGE method was used for isolation of the plasmid as per the standard protocol (Armstrong,1983).

\section{B. Isolation and processing of Bacterial Proteins}

The bacterial cells were lysed and precipitated by centrifugation. The supernatant was collected for the isolation of bacterial proteins. The supernatant broth was supersaturated with Ammonium Sulphate under cold conditions and stored at $4{ }^{\circ} \mathrm{C}$ overnight. The broth was centrifuged at $10000 \mathrm{rpm}$ for 10 minutes and the supernatant was discarded. The pellet was suspended in Phosphate buffered saline (pH 7.0) (Rosenberg,2005) The protein pellet was dialyzed against Dialysis buffer. The proteins thus obtained were assessed quantitatively by Biuret Method. The biuret method depends on the presence of peptides bonds in proteins. Biuret reagent is an alkaline copper sulfate solution (Copper Sulfate, $\mathrm{NaOH}$ ). When a solution of proteins is treated with cupric ions $\left(\mathrm{Cu}^{2+}\right)$ in a moderately alkaline medium, a purple colored $\mathrm{Cu}^{2+}$ peptide complex (purple chelates) is formed. The intensity of the color produced is proportional to the number of peptide bonds that are reacting, and therefore to the number of protein molecules present in the reaction system. The intensity can be measured quantitatively by spectrophotometer in the visible region at $560 \mathrm{~nm}$.

\section{Separation of Proteins}

Partially purified proteins were separated by Polyacrylamide Gel Electrophoresis. The 6\% polyacrylamide gel was prepared by using 30\% Polyacrylamide, $10 \%$ Ammonium persulfate, TEMED, Tris $-\mathrm{HCl}(\mathrm{pH} 8.3-8.6)$. The gel was set in gel casting set up of vertical electrophoretic apparatus (Genei, India) as per the standard protocols (Rosenberg,2005). The sample was diluted with gel loading dye comprising Bromophenol blue for tracking purpose. 20 $\mu l$ of the sample was loaded in each well. At an electric current of $100 \mathrm{~V}$, considering Tris- Glycien buffer (pH8.6) as tank buffer the gel electrophoresis was run for 2-3 hours. The gel was stained with Staining Solution (Coomassie brilliant blue R250, Methanol, Distilled water, Glacial Acetic Acid) for an hour. Destaining of the gel was carried out till sharp bands started appearing (Walker ,2002).

Assessment of Restriction digestion capability of proteins extracted from E.coli, K. pneumoniae \& $S$. aureus from the supernatant of culture media was carrried out using the plasmids extracted from bacteria (E.coli, K.pneumoniae,S. aureus) and yeast ( S.cereveseae) as substrates. . A common restriction buffer was used while assessing the activity which contained Tris - $\mathrm{HCl}$, Magnesium chloride, Potassium chloride, Dithiothreitol. 


\section{Standard protocol for Restriction digestion:}

The requirements for restriction digestion were mixed as per the standard protocol table (Table-1) The mixture was spun at $8000 \mathrm{rpm}$ for 1 minute and incubated at $37{ }^{\circ} \mathrm{C}$ for 2 hours.. Mixture spun at 8000 rpm for 1 minute. AGE was performed to check restriction fragments.

Agarose Gel Electrophoresis: The plasmid extracts and restriction digests of DNA and plasmid were observed on agarose gel prepared in TAE buffer after Agarose gel electrophoresis as mentioned in the standard protocols (Rosenberg,2005). 0.8\% agarose gel was prepared comprising $20 \mu \mathrm{l}$ Ethidium Bromide. The sample was diluted with tracking dye in the ratio of 5:1. $20 \mu 1$ of the sample was loaded in different wells. An electric current of $100 \mathrm{~V}$ was applied. DNA bands were visualized in the gel using U.V. trans-illuminator at 265 $\mathrm{nm}$ (Short wavelength) and $365 \mathrm{~nm}$ (long wavelength).

\begin{tabular}{|l|l|l|}
\hline Reagents & Test & Sample \\
\hline DNA pellets & $4 \mu \mathrm{l}$ & $4 \mu \mathrm{l}$ \\
\hline Restriction buffer (10X) & $2 \mu \mathrm{l}$ & $2 \mu \mathrm{l}$ \\
\hline $\begin{array}{l}\text { Enzyme (Crude protein } \\
\text { extract) }\end{array}$ & $10 \mu \mathrm{l}$ & - \\
\hline Distilled water & $13 \mu \mathrm{l}$ & $23 \mu \mathrm{l}$ \\
\hline Loading dye & $5 \mu \mathrm{l}$ & $5 \mu \mathrm{l}$ \\
\hline
\end{tabular}

Table-1: Standard protocol for restriction digestion

\section{RESULTS}

\section{A. Plasmid Extraction:}

The standard protocol of alkaline Lysis method was followed to extract the plasmid DNAs of laboratory microbes such as $S$. aureus, E. coli, $K$. pneumonia, and $S$. cerevisiae were obtained in the form of white pellets. The pellets were suspended in TE buffer ( $\mathrm{pH}$ 8.0) prior to the use of restriction digestion by the proteins extracted from the same bacterial species.

\section{B. Protein Concentration:}

Proteins from the nutrient broth were separated by salting and desalting procedures. The obtained protein pellet was dissolved in PBS and their concentration was estimated by Biuret Method. The concentration of protein in the sample varied from $8 \pm 0.2 \mathrm{mg} / \mathrm{ml}$. However, the protein extracted from the broth concentration was more for Klebsiella pneumoniae bacteria than the others.

\section{Identification of bands:}

The extracted protein samples of different bacteria were isolated on native PAGE. Four different bands for each protein sample were detected on the gel stained with CBB R250 whereas five bands were detected for the marker. The Rf values of the protein band number 1, 2 and 4 of the sample matched with the $\mathrm{Rf}$ values of marker protein band number 1, 4 and 6 and thus their molecular weights were known. The Rf values of protein band number 3 of the sample did not match with any of the protein marker bands. The molecular weights of these bands were calculated (Rosenberg,2005). The $\log 10$ of the molecular weights were plotted against their $\mathrm{Rf}$ values. The $\mathrm{Rf}$ values of the unknown were extrapolated on the standard graph. Antilog of the same gives the molecular weight of the band. All the bacterial proteins showed a similar banding pattern and approximately equal Rf values. The molecular weights of the bands were found to be $14 \pm 0.1 \mathrm{kDa} ; 15 \pm 0.1 \mathrm{kDa}$. $29 \pm$ $0.1 \mathrm{kDa}$, and $66 \pm 0.1 \mathrm{kDa}$ in case of $S$. aureus, E. coli, and K. pneumoniae. (Fig.1)

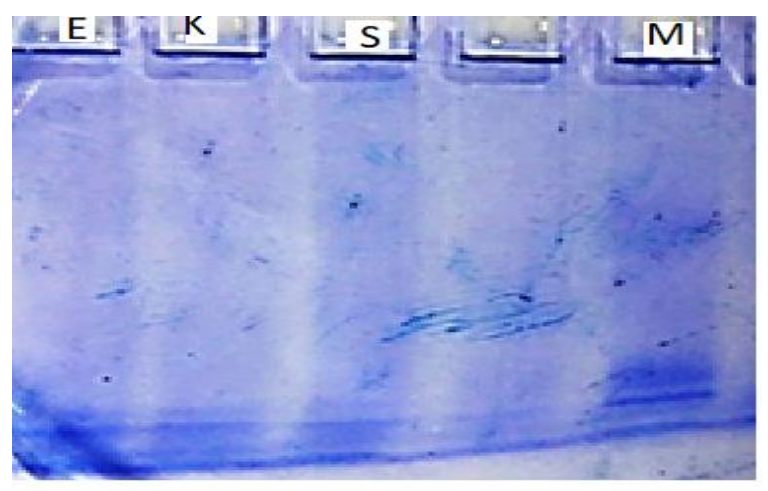

Fig. 1: Protein bands of sample and marker after PAGE ( E-Escherichia coli.; K-Klebsiella pneumoniae.;S-Staphylococcus aureus, M-Marker)

The Agarose gel electrophoresis indicated that the plasmids of yeast were effectively digested by the proteins of the three bacterial strains indicating that they represent the restriction enzymes. Similarly, the extracted proteins of the three bacterial strains effectively broken the plasmids of each other indicating that they can be effectively used for digestion of DNA (Fig.2). The overall study indicated that restriction enzymes extracted from the laboratory strains of 


\section{International Journal of Engineering Applied Sciences and Technology, 2019 \\ Vol. 4, Issue 6, ISSN No. 2455-2143, Pages 92-98 \\ Published Online October 2019 in IJEAST (http://www.ijeast.com)}

bacteria can be effective and can be used for academic purposes

\section{DISCUSSION}

A number of restriction enzymes are isolated from bacteria where they are thought to play a role in host defense by cutting and destroying foreign DNA, for example, of invading viruses. The methods such as alternating sonication with cooling on the ice were used to disrupt cells, protein purification and extraction by His Trap, Exclusion, and DEAE anion exchange chromatography followed SDS PAGE for the isolation (Loenen et.al., 2013) In the current method, a simple method of using glass beads to disrupt cells and to extract proteins/restriction enzymes.

Type I enzyme (Roberts et.al., 2013) Type II enzymes, purification procedures comprised a highspeed supernatant of a cell lysate, removal of nucleic acids by streptomycin or polyethyleneimine and several column chromatography techniques (Phosphocellulose, DEAE-cellulose, hydroxyapatite, and gel filtration). Preparations were purified to reduce the interfering activities, but usually not to homogeneity (Pingoud et.al., 2014).

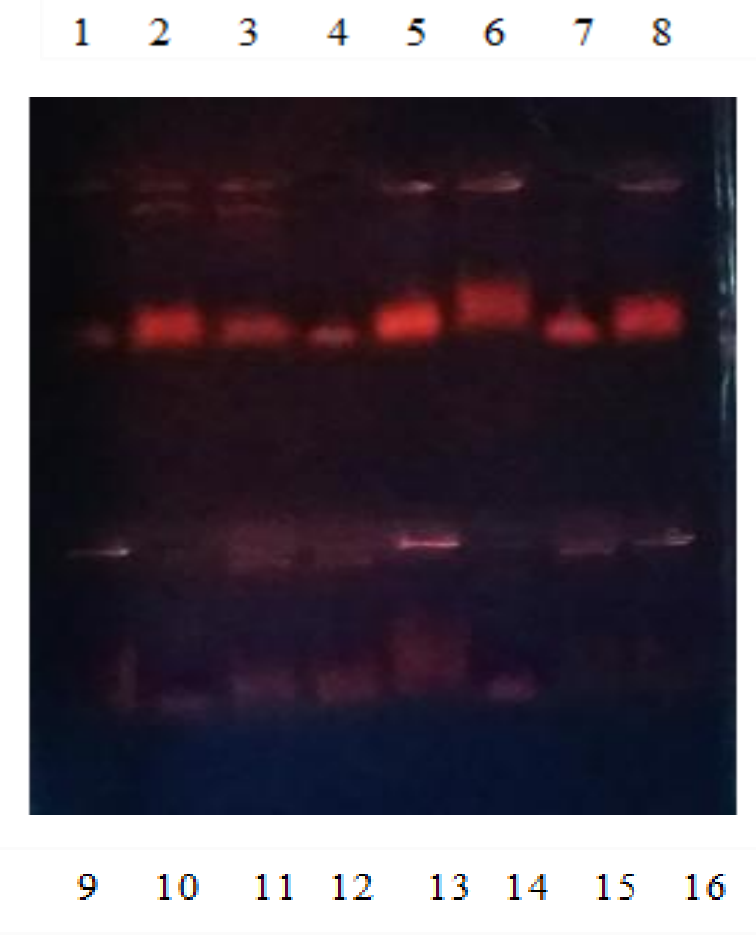

1 - Yeast Plasmid Control ; 2, 3, 4, 5, 6 - Action of $E$. coli 1, E. coli 2, kit, $S$. aureus, and $K$. pneumoniae proteins on yeast plasmid resp.; 7- E. coli plasmid control; 8, 9 - Action of $S$. aureus, and $K$. pneumoniae proteins on $E$. coli plasmid resp.; 10 - S. aureus plasmid control; 11, 12, 13 - Action of E. coli 1, E. coli 2 , and $K$. pneumoniae proteins on $S$. aureus plasmid resp.; 14 - K. pneumoniae plasmid control; 15, 16 Action of $E$. coli and $S$. aureus, proteins on $K$. pneumoniae plasmid respectively.

Fig. 2: Visualization of Restriction fragments after AGE

Crude lysates of $E$. coli $\mathrm{K}(\mathrm{P} 1)$ exhibited no apparent REase activity. But fractionation gave an enzymatic activity, which specifically cleaved the phage DNA (Kasarjian, 2005) Hinf III REase was purified from restricting strains using phospho-cellulose and DNAagarose chromatography (Rao et.al., 2013). Similarly, sequence of restriction endonuclease Kpnl from Klebsiella pneumonia was extracted and identified whose specific activity 50,000 units/mg (Tomassini et.al.,978). Class II Restriction Endonuclease from Staphylococcus aureus was obtained by suspending cells in $8 \mathrm{ml}$ of (Tris)-hydrochloride and B-mercapto ethanol buffer ( $\mathrm{pH}$ 7.4), cell disruption by sonic treatment at $0^{\circ} \mathrm{C}$ followed by centrifugation. The supernatant was collected, and nucleic acids were precipitated by streptomycin sulfate $(2 \mathrm{ml}$ of a $10 \%$ streptomycin sulfate solution in $0.01 \mathrm{M}$ Trishydrochloride-0.01 M /3-mercaptoethanol, $\mathrm{pH}$ 7.4) followed by centrifugation. The supernatant was dialyzed against $0.01 \mathrm{M}$ Tris-hydrochloride to $0.01 \mathrm{M}$ f 3-mercaptoethanol, pH 7.4. The crude extract (about $10 \mathrm{ml}$ ) was tested for the presence of endo-nucleolytic activity (Stobberingh ,et.al.,1977; Xu et.al.,2011).

In the current study, an attempt was made to isolate restriction endonucleases indigenously from common laboratory bacteria with basic laboratory techniques during the current study. The enzymes were isolated by a general cell lysis method (Bimboim and Doly,1979; Sobanski and Dickinson 1995). The lysate was subjected to partial purification by precipitation with ammonium sulfate (salting) followed by desalting. The crude extracts were also electrophoresed using polyacrylamide gel. Four different bands for each protein sample were detected whereas five bands were detected for the marker. Out of four bands, the $\mathrm{Rf}$ values of three matched with that of the marker. The molecular weights of these proteins were calculated to be $14 \pm 0.1 \mathrm{kDa}, 15 \pm 0.1 \mathrm{kDa}, 29 \pm 0.1 \mathrm{kDa}$, and $66 \pm$ 


\section{International Journal of Engineering Applied Sciences and Technology, 2019 \\ Vol. 4, Issue 6, ISSN No. 2455-2143, Pages 92-98 \\ Published Online October 2019 in IJEAST (http://www.ijeast.com)}

$0.1 \mathrm{kDa}$ in case of $S$. aureus, E. coli, and $K$. pneumoniae.

The crude extract was assessed for digestion activity by incubating with the plasmids as per the standard procedure as mentioned earlier. Restriction fragments were detected by Agarose gel electrophoresis using Ethidium Bromide as an intercalating substance and fluoresce wherever the DNA fragments were found. In this study, after AGE, test samples showed more bands as compared to the control. This indicates the crude extracts possess restriction digestion activity. Also, with respect to the commercial kit, the crude extracts showed comparable activity.

The isolated proteins from the selected bacterial species of laboratory were checked for effective restriction digestion against the other bacterial and yeast plasmids. For example, the proteins isolated from S.aureus were checked against the plasmids of E.coli, $K$ pneumoniae and $S$ cereviseae. The restriction digestion activity found to be effective. The proteins extracted from broth of S. aureus, E. coli, and $K$. pneumoniae cultures can be considered as restriction enzymes. The crude extract thus obtained was showed significant digestion activity. Also, the plasmids against which the digestion activity was tested were obtained from common laboratory bacteria by a standard cell lysis method. However, no further purification steps were carried out.

Each restriction modification system has a different mechanism of action as well as physical and chemical requirements. There are several important factors to consider when using restriction enzymes such as buffer composition, incubation temperature, DNA methylation, and star activity. Buffers vary with respective to the type of enzyme and mode of action as they have different preferences with respect to ionic strength and cations such as Sodium and potassium. There is no universal common digestion buffer for restriction enzymes There are 3-4 commonly used buffers that are generally used for most enzyme conditions. Most enzymes work around $\mathrm{pH} 8.0$, however, some enzymes are more particular and have specific buffers. Buffer systems may vary with respect to components such as Bis-Tris-Propane-HCl/ Tris $\mathrm{HCl}, \mathrm{MgCl}_{2}, \mathrm{NaCl}$ and Dithiothreitol, and their concentrations, $\mathrm{pH}$ and temperature conditions depending on the type of restriction enzymes origin. However, in this study, a single universal digestion buffer was developed and used for assessment of digestion efficiency of all restriction endonucleases. Minimal facilities were required for the storage of these enzymes. The commercially available enzymes are costly; require high maintenance and waiting time to procure them is long. An attempt was made to develop a cost-effective method to procure restriction enzymes

\section{CONCLUSION}

The use of restriction enzymes has proved invaluable in molecular biology, cloning, genetic engineering, immunology, forensic analysis and a number of other scientific disciplines such as the creation of gene libraries ( Durmaz et al. 2015, Heather and Chain 2016). However, the cost of these enzymes limits their use and applications. Thus, there is an absolute need to devise an alternative way to obtain the restriction enzymes. An attempt was made to develop a cost-effective method to procure restriction enzymes indigenously with minimal facilities for production, maintenance, and storage during the study. The cost is further reduced by the use of a single universal buffer for all enzymes. This also reduces the waiting time for procuring the enzymes. Also, the enzymes obtained show a broad spectrum of activity, as they work on eukaryotic as well as prokaryotic plasmid DNA. As of now, these enzymes can be used for academic purposes, to teach students the concepts and give them hands-on training. However, after further analysis, these can be commercialized as well.

\section{ACKNOWLEDGEMENTS}

The authors heartily thank the SVKM management for the facilities provided for research, and the Principal for his guidance and encouragement during the study.

\section{REFERENCES}

[1] Arber W., and Linn S (1969). DNA modification and restriction. Annu.Rev.Biochem. 38:467-500.

[2] Armstrong K. (1983). Molecular Cloning: A Laboratory Manual T. Maniatis E. F. Fritsch J. Sambrook. The Quarterly Review of Biology, 58(2):234-234.

[3] Arun Kumar A., Nozomu H., and Tsuguto F.(2014) Simple and Cost-Effective Restriction Endonuclease Analysis of Human Adenoviruses BioMed Research International. Article ID 363790, 6 pgs

[4] Bimboim H., and Doly J. (1979). A rapid alkaline extraction procedure for screening recombinant plasmid DNA. Nucl Acids Res, 7(6):1513-1523.

[5] Durmaz A.A, Karaca E, Demkow U, Toruner G, Schoumans J and Cogulu O (2015) Evolution of genetic techniques: Past, present, and beyond [WWW 


\section{International Journal of Engineering Applied Sciences and Technology, 2019 \\ Vol. 4, Issue 6, ISSN No. 2455-2143, Pages 92-98 \\ Published Online October 2019 in IJEAST (http://www.ijeast.com)}

document]. BioMed Res. Int. https://doi. org/10.1155/2015/461524

[6] Francesca D.F., Gioacchino M and Giorgio C. Restriction enzymes and their use in molecular biology: An overview. (2019) J Biosci 44:38.

[7] Heather JM and Chain B 2016 The sequence of sequencers: The history of sequencing DNA. Genomics 107 1-8

[8] Kado C., and Liu S. (1981). Rapid Procedure for Detection and Isolation of Large and Small Plasmids. Journal of bacteriology, 145(3):1365-1373.

[9] Kasarjian J. (2005). Four new type I restriction enzymes identified in Escherichia coli clinical isolates. Nucleic Acids Research, 33(13) :e114-e114.

[10] Kelly TJ Jr., and Smith HO (1970). A restriction enzyme from Hemophilus influenzae. IIJ Mol Biol. 28;51(2):393-409

[11] Loenen W., Dryden D., Raleigh E., Wilson G., and Murray N. (2013). Highlights of the DNA cutters: a short history of the restriction enzymes. Nucleic Acids Research, 42(1) :3-19.

[12] Mertz J.E., and Davis RW.(1972) Cleavage of DNA by $\mathrm{R} 1$ restriction endonuclease generates cohesive ends. Proc Natl Acad Sci U S A. 69(11):3370-4

[13] Pingoud A., Wilson G., and Wende W. (2014). Type II restriction endonucleases - a historical perspective and more. Nucleic Acids Res, 42(12) :7489-7527.

[14] Rao D., Dryden D., and Bheema Naik S. (2013). Type III restriction-modification enzymes: a historical perspective. Nucleic Acids Research, 42(1) : 45-55.
[15] Roberts G., Houston P., White J., Chen K., Stephanou A., Cooper L., Dryden D., and Lindsay J. (2013). Impact of target site distribution for Type I restriction enzymes on the evolution of methicillinresistant Staphylococcus aureus (MRSA) populations. Nucleic Acids Research, 41(15) : 7472-7484.

[16] Rosenberg I. (2005). Protein analysis and purification. Boston: Birkhäuser.

[17] Seed K. (2015). Battling Phages: How Bacteria Defend against Viral Attack. PLoS Pathog, [online] 11(6), p.e1004847.

[18] Sobanski M., and Dickinson J. (1995). A simple method for the direct extraction of plasmid DNA from yeast. Biotechnology Tech, 9(3) : 225-230.

[19] Stobberingh E., Schiphof R., and Sussenbach J. (1977). Occurrence of a Class II Restriction Endonuclease in Staphylococcus aureus. Journal Of Bacteriology 131(2):645 - 649.

[20] Tomassini J., Roychoudhury R., Wu R., and Roberts R. (1978). Recognition sequence of restriction endonuclease $\mathrm{KpnI}$ from Klebsiella pneumoniae. $\mathrm{Nucl}$ Acids Res, 5(11):4055-4064.

[21] Walker J. (2002). The protein protocols handbook. Totowa, N.J.: Humana Press.

[22] Xu, S., Corvaglia, A., Chan, S., Zheng, Y. and Linder, P. (2011). A type IV modification-dependent restriction enzyme SauUSI from Staphylococcus aureus subsp. aureus USA300. Nucleic Acids Research, 39(13), pp.5597-5610. 